\title{
Rear-foot kinematics in runners with PFPS during walking, squatting and uphill running
}

\author{
Jessica Leitch ${ }^{1 *}$, Kathleen Reilly², Julie Stebbins ${ }^{3}$, Amy B Zavatsky $^{1}$ \\ From 3rd Congress of the International Foot and Ankle Biomechanics Community \\ Sydney, Australia. 11-13 April 2012
}

\begin{abstract}
Background
Patellofemoral pain syndrome (PFPS) is the most common overuse injury in distance runners. A pilot investigation found that runners with a history of PFPS exhibited increased rear-foot eversion and reduced rear-foot dorsiflexion compared to uninjured controls during level treadmill running [1]. The aim of the present study was to investigate whether these kinematic alterations were also demonstrated during activities that demanded more dorsiflexion (uphill running and squatting) and less dorsiflexion (walking) compared to level running.
\end{abstract}

\section{Materials and methods}

Nine female runners with a previous history of PFPS and ten female controls participated in the study. Spherical reflective markers $(9-\mathrm{mm})$ were attached to anatomical landmarks of both lower limbs [2]. A 12-camera Vicon MX System (Vicon Motion Systems, Oxford, UK) was used to collect 3-D spatial data at $200 \mathrm{~Hz}$ as the subject performed (i) five over-ground walking strides (self-selected speed), (ii) five squats and (iii) five uphill running strides on a treadmill (speed $=2.96 \mathrm{~ms}^{-1}$, incline $=10^{\circ}$ ). Rear-foot joint angles were calculated using the Oxford Foot Model [2]. The five trials for each activity and each subject were normalised to the stance (squat) period using cubic spline interpolation. Discrete kinematic parameters (peak rear-foot dorsiflexion, dorsiflexion excursion, peak rear-foot eversion) were identified for each of the five trials of each subject. The variables were compared between groups using one-tailed $t$-tests with an alpha level set at 0.05 .

\section{Results}

Subjects with a history of PFPS demonstrated significantly less dorsiflexion (peak) during walking and squatting compared to uninjured controls (Table 1). Dorsiflexion excursion was significantly lower and rear-foot eversion significantly higher in subjects with a history of PFPS compared to uninjured controls during uphill running.

\section{Conclusion}

The kinematic alterations that had been observed in subjects with a history of PFPS during level running [1] were also apparent during walking, uphill running and squatting. Further investigations to understand the relationship between rear-foot joint motion and patellofemoral joint kinematics are required.

Table 1 Kinematic parameters during walking, running and squatting for subjects with a history of PFPS (P) and uninjured controls $(N) .{ }^{*}$ Indicates a statistically significant difference $(p<0.05)$

\begin{tabular}{|c|c|c|c|c|c|c|c|c|c|}
\hline & \multicolumn{3}{|c|}{ Walk } & \multicolumn{3}{|c|}{ Uphill Run } & \multicolumn{3}{|c|}{ Squat } \\
\hline Angle $\left({ }^{\circ}\right)$ & $\mathrm{N}$ & $P$ & $p$-value & $\mathrm{N}$ & $P$ & $p$-value & $\mathrm{N}$ & $P$ & $p$-value \\
\hline Peak dorsiflexion & $11.2(3.2)$ & $7.9(2.8)$ & $0.01 *$ & $18.9(7.2)$ & $15.9(2.5)$ & 0.13 & $25.0(8.2)$ & $19.0(3.3)$ & $0.03^{*}$ \\
\hline Dorsiflexion excursion & $17.0(2.5)$ & $15.1(2.8)$ & 0.06 & $17.5(3.8)$ & $14.0(2.3)$ & $0.04^{*}$ & $19.5(8.8)$ & $17.0(2.5)$ & 0.21 \\
\hline Peak eversion & $5.8(6.2)$ & $9.5(3.3)$ & 0.07 & $7.1(7.5)$ & $12.8(3.1)$ & $0.03^{*}$ & $6.5(10.8)$ & $10.1(3.2)$ & 0.18 \\
\hline
\end{tabular}

\footnotetext{
* Correspondence: Jessica.Leitch@noc.nhs.uk

'Department of Engineering Science, University of Oxford, Oxford, OX1 3PJ,

UK

Full list of author information is available at the end of the article
}

(c) 2012 Leitch et al; licensee BioMed Central Ltd. This is an Open Access article distributed under the terms of the Creative Commons 


\section{Author details}

'Department of Engineering Science, University of Oxford, Oxford, OX1 3PJ,

UK. ${ }^{2}$ Department of Physiotherapy, Nuffield Orthopaedic Centre, Oxford, OX3

7LD, UK. ${ }^{3}$ Oxford Gait Laboratory, Nuffield Orthopaedic Centre, Oxford, OX3

7LD, UK.

Published: 10 April 2012

\section{References}

1. Leitch J, Reilly K, Stebbins J, Zavatsky AB: Lower-limb and foot kinematics in distance runners with patellofemoral pain syndrome. Proceedings of the 2nd Patellofemoral Pain Syndrome International Research Retreat: August 2011; Ghent,Belgium .

2. Stebbins J, Harrington M, Thompson N, Zavatsky AB, Theologis T:

Repeatability of a model for measuring multi-segment foot kinematics in children. Gait Posture 2006, 23:401-410.

doi:10.1186/1757-1146-5-S1-P26

Cite this article as: Leitch et al:: Rear-foot kinematics in runners with PFPS during walking, squatting and uphill running. Journal of Foot and Ankle Research 2012 5(Suppl 1):P26.

\section{Submit your next manuscript to BioMed Central} and take full advantage of:

- Convenient online submission

- Thorough peer review

- No space constraints or color figure charges

- Immediate publication on acceptance

- Inclusion in PubMed, CAS, Scopus and Google Scholar

- Research which is freely available for redistribution

Submit your manuscript at www.biomedcentral.com/submit 